\title{
Dimensões da Cibercultura no Brasil
}

\author{
Fabián Echegaray
}

Market Analysis Brasil

\begin{abstract}
Resumo
Este artigo ilustra os efeitos do uso da Internet sobre aspectos atitudinais e comportamentais e descreve diferentes formas nas quais o modo de relação dos usuários com a Internet podem ser descritas e classificadas para os propósitos da análise de segmentação, no Brasil. Primeiro, diferenças entre grupos de usuários e não-usuários são examinadas baseadas em um conjunto de surveys com a população global. Em seguida, uma nova categorização de modos de relacionamento com a Internet, é proposta, usando padrões de informação de uso. Finalmente, o peso relativo desta abordagem, vis-à-vis classificações padrão, explicando hábitos e posturas dos usuários sobre questões relacionadas às esferas do consumo e da política.
\end{abstract}

Palavras-chave: Internet, análise de segmentação, comunicação, cidadão digital

\begin{abstract}
This paper illustrates the effects of Internet usage on attitudinal and behavioral aspects and describes different ways in which users' mode of relationship with the Internet can be profiled and classified for segmentation and analysis purposes, in Brazil. First, differences between-groups of users and non-users are examined based on series of general population sample survey studies. Following this, a new categorization of modes of relationship with the Internet is proposed using information of usage patterns. Finally, I test the relative leverage of this approach, vis-à-vis more standard classifications, in explaining users' habits and postures on issues related to the spheres of consumption and politics.
\end{abstract}

Key words: Internet, targeting approach, communication, digital citizen 


\section{Introdução}

A expansão da Internet no Brasil constitui-se um dos maiores fenômenos econômicos dos últimos tempos, ainda mais se pensada no contexto de recessão ou lento crescimento da economia. Atualmente, a mídia relata notícias relacionadas à Internet com a mesma normalidade e freqüência que qualquer empreendimento econômico ou fenômeno social. As empresas alinham seus investimentos relacionados à Internet em conjunto com outros gastos anuais cotidianos e o governo compõe a propaganda tanto quanto os programas sociais.

Atualmente, o Brasil representa mais de $40 \%$ de usuários da América Latina e a indústria da Internet movimenta bilhões de dólares no país em compras negociadas entre empresas (B2B-business to business), entre consumidores (C2C) e em negócios diretos com o consumidor (business to consumer-B2C), com a expectativa de alcançar 2.7 bilhões de dólares em $2003^{1}$.

Sabemos cada dia mais sobre seus efeitos econômicos, mas, e sobre suas repercussões culturais? Qual é seu efeito sobre grupos de consumidores individuais e cidadãos na sociedade brasileira? Como a Internet impacta os aspectos cotidianos da vida? Este artigo objetiva discutir essas questões sob uma perspectiva empírica ${ }^{2}$, com base em duas hipóteses mais amplas: a primeira, que os efeitos da Internet podem ser claramente distinguidos entre usuários e não-usuários, e a segunda, que os usuários da Internet não compõem um bloco homogêneo, no sentido de que as formas de relacionamento entre o usuário e a Internet apresentam distinções importantes que requerem melhor medida e compreensão sobre seu impacto.

\footnotetext{
${ }^{1}$ Cf. Jornal Folha de S.Paulo, 2 jan. 2001; Jornal Gazeta Mercantil, 11 fev. 2001

2 Todos os dados apresentados provêm de estudos de surveys, coletados pela Market Analysis Brasil, uma organização brasileira de pesquisa de opinião e mercado. Em todos os casos, as amostras refletem características reais da população residente adulta, com idade entre 18 e 69 anos, em 5 dos 8 principais centros urbanos do país: São Paulo, Rio de Janeiro, Belo Horizonte, Recife e Porto Alegre. As entrevistas foram realizadas face-a-face ao nível domiciliar, a partir de uma amostragem de clusters pré-estratificados selecionados aleatoriamente com aplicação de cotas no nível dos entrevistados. O tamanho das amostras varia entre 509 e 669 casos, distribuídos proporcionalmente ao tamanho da população de cada cidade.
} 


\title{
O fenômeno da Internet
}

\author{
O aumento da familiaridade
}

A familiaridade com novos produtos e serviços tem tradicionalmente servido como medida básica para avaliar a dimensão das inovações. A extensão na qual os indivíduos desenvolvem pouca ou muita familiaridade revela o grau de penetração subjetiva que cada categoria obteve. A familiaridade é uma pré-condição, assim como um preditor-chave de uso e adoção. Nesse sentido, familiaridade é um tipo de variável com probabilidade de ilustrar as prospectivas para os novos bens.

Durante os 12 meses entre dezembro de 1999 e dezembro de 2000, os não informados sobre a Internet despencaram de quase um terço da população urbana adulta para ínfimos $6 \%$. Isso significa que a familiaridade não é mais uma questão, dado que transformou-se de variável em constante: quase todo mundo já ouviu falar sobre ela.

\section{Tabela 1}

\section{Familiaridade com a Internet}

\begin{tabular}{|l|c|c|c|}
\hline & Dez.1999 & Jul. 2000 & Dez.2000 \\
\hline Conhece muito sobre ela & $7 \%$ & $15 \%$ & $19 \%$ \\
\hline Já ouviu falar mas não sabe muito & $63 \%$ & $77 \%$ & $75 \%$ \\
\hline Não ouviu falar + não sabe/não respondeu & $30 \%$ & $9 \%$ & $6 \%$ \\
\hline Total & $100 \%$ & $100 \%$ & $100 \%$ \\
\hline $\mathrm{N}=$ & 669 & 509 & 541 \\
\hline
\end{tabular}

(questão:Tem-se falado sobre a Internet. Algumas pessoas devem ter ouvido ou lido sobre a Internet, outras não. E você? Você diria que....?) 
Tal evolução significa que a Internet enquanto um fenômeno tornou-se familiar para pessoas de todas as classes sociais, idades e regiões do Brasil. Pequenas diferenças permanecem, mas não são mais significativas.

Tabela 2

Falta de familiaridade entre sub-grupos entrevistados que responderam "não ouviram' ou 'não sabe/ não respondeu'

\begin{tabular}{|c|c|c|c|}
\hline Sub-Grupos & Dez.1999 & Julho 2000 & Dez.2000 \\
\hline Segmentos A e B & $1 \%$ & $<1 \%$ & $<0 \%$ \\
\hline Segmentos D e E & $16 \%$ & $11 \%$ & $4 \%$ \\
\hline Coorte mais jovem (18.35) & $4 \%$ & $5 \%$ & $2 \%$ \\
\hline Coorte mais velha (36.69) & $14 \%$ & $12 \%$ & $4.5 \%$ \\
\hline
\end{tabular}

A familiaridade pode predizer a adoção, o que é diferente de garanti-la. No Brasil, o acesso à Internet envolve mais do que apenas atitude; requer acesso a ambientes específicos ( trabalho, escola, amigos e parentes "ligados", consumo mínimo em cibercafés), quando essas infra-estruturas não estão presentes em casa. Isso ocorre porque, infelizmente, na maioria das vezes o acesso público às bibliotecas não é disponível. Como resultado, a crescente familiaridade combina-se a um lento crescimento do uso real da Internet.

\section{Tabela 3}

Uso da Internet nas principais capitais

\begin{tabular}{|l|c|c|c|c|}
\hline & Dez.1999 & Março 2000 & Julho 2000 & Dez.2000 \\
\hline Usuários da Internet-último mês & $17 \%$ & $19 \%$ & $18 \%$ & $20 \%$ \\
\hline Segmento D e E & $4 \%$ & $7 \%$ & $7 \%$ & $6 \%$ \\
\hline Coorte mais jovem & $69 \%$ & $63 \%$ & $69 \%$ & $69 \%$ \\
\hline Coorte mais velha & $31 \%$ & $37 \%$ & $31 \%$ & $31 \%$ \\
\hline
\end{tabular}

Questão: Você acessou a Internet no último mês/ 30 dias? 
Esse crescimento apresenta duas características:

a) tem sido muito tímido, embora consistentemente crescente em um período mais longo, e

b) está ainda longe de definir uma expansão horizontal/vertical: em outras palavras, ainda é predominantemente um "jogo de elite" (os segmentos sociais A, B e C, que representam perto de $60 \%$ dos setores mais altos da sociedade, mas que respondem por quase $95 \%$ dos usuários); e ainda é a opção para a metade mais jovem da população adulta (18-35 anos de idade)

\section{Então... estamos olhando para uma nova cultura?}

As visões sobre o lado cultural da Internet têm permanecido tanto incompletas quanto pouco confiáveis no Brasil. Algumas apresentam-no como mais outra manifestação da sofisticação do consumo pelas classes mais altas; outras interpretam-no como restrito aos hábitos de lazer de coortes adolescentes; outras ainda atribuem a explosão cultural da Internet à uma inclinação psicológica interna, que a torna um fenômeno exclusivo dos tímidos e antisociais e, finalmente, algumas a apresentam como uma realidade apenas do mundo seleto das corporações.

Em qualquer caso, quase todas as referências compartilham duas características comuns: foram circunscritas basicamente a artigos e interpretações feitas pela mídia, e tratadas como parte ou projeção de um outro aspecto de maior relevância (classes altas, adolescência, mundo dos negócios,etc), isto é, como um fenômeno sem vida própria. A única exceção, parcial, é o trabalho de Nicolaci da Costa (1998), que claramente fala de um novo fenômeno cultural, após uma descrição semi-antropológica da linguagem, usos e rituais de alguns usuários. 0 esforço inicial, entretanto, teve difícil ressonância entre estudiosos e pesquisadores de mercado, exceto por uma tendência regular de descrever o perfil brasileiro dos usuários de Internet (COSTA, 1998).

Mesmo quando um importante periódico trouxe o debate vívido que acontecia nos Estados Unidos sobre a "nação digital", nenhum esforço foi feito para observar empiricamente esse fenômeno de maneira ampla. Em contraste com as entusiásticas interpretações inspiradas pelo famoso survey "Wired/Merril Lynch Forum do Cidadão Digital", o fenômeno da Internet no Brasil permaneceu sem estudo e sem mensuração. 
Essa ausência de discussão empírica obstruiu as afirmativas de que um profundo evento cultural tem emergido. Observadores, clientes e pesquisadores de mercado têm dito que observar a nova elite é como ter uma janela olhando para o futuro sobre como consumidores e cidadãos agem e reagem. Dessa forma, as comparações empíricas sobre os hábitos e orientações da minoria 'plugada' contra a maioria 'não plugada' ficam sempre para um momento posterior, como uma promessa a ser cumprida.

Meu argumento é que o uso da Internet constitui um fenômeno cultural em si mesmo e, é claro, usuários da Internet são distintos dos não-usuários para além dos dados demográficos, com diferenças amplas: da sua capacidade de articular opiniões a estilos de vida, do impacto das marcas à definição de prioridades, de suas visões sobre a economia às preferências políticas.

Para sustentar essas afirmações, apresento dados comparados dos que são usualmente chamados de usuários de Internet 'ativos' (aqueles que acessaram a Internet ao menos uma vez nos últimos 30 dias) com aqueles que afirmam não tê-la acessado nunca.

Em todos os casos, considero as diferenças iguais ou maiores que $5 \%$ entre os dois grupos que, como regra, apresentam-se estatisticamente significantes $(p<.10$ ou melhor $)$.

Hipóteses 1 a e 1 b: Contrastes na capacidade de opinar e níveis de informação

Um aspecto essencial é o grau com que as pessoas verbalizam e expõem respostas a estímulos e questões que, mais ou menos, fazem parte de sua vida cotidiana. Meu argumento é que existem diferenças importantes entre usuários e não-usuários na capacidade de emitir julgamentos e formar e expressar preferências.

Em um nível cumulativo e agregado, tais diferenças básicas distinguem consumidores, que podem de forma ativa e independente conectar vontades e necessidades a produtos e escolhas de marcas, e cidadãos, que podem comportarse de maneira participativa em vez de simples sujeitos.

Uma forma de testar isso é pela comparação de indexes somatórios de respostas "não sei/ não respondeu" a questões de comércio e político-econômicas entre grupos. 


\section{Tabela 4}

Contrastes em articulação de opinião e conhecimento entre usuários e nãousuários de Internet (diferença percentual para não-usuários)

\begin{tabular}{|r|c|}
\hline A - questões de não-opinião & $\%$ Dif. \\
\hline Principais marcas internacionais (\% média de 5 marcas) & $+29 \%$ \\
\hline Temas básicos sobre economia e governo democrático (\% média de 10 temas) & $+28 \%$ \\
\hline Principais marcas internacionais II (\% média de 6 marcas) & $+21 \%$ \\
\hline Confiança nas 6 principais instituições globais/atores (média) & $+8 \%$ \\
\hline Atribuição a país pelo melhor desempenho na produção de produtos e serviços & $+7 \%$ \\
gerais (média de 8 itens) & \\
\hline Proposta do Terceiro Mundo para cancelamento da dívida & $+38 \%$ \\
\hline Alimento geneticamente modificado & $+36 \%$ \\
\hline Organização Mundial de Comércio & $+32 \%$ \\
\hline Conflito do Oriente Médio & $+21 \%$ \\
\hline Efeito Bug 2000 & $+20 \%$ \\
\hline Eferença de conhecimento do envolvimento dos EUA na política mundial (média de 3 áreas) & $+12 \%$ \\
\hline Efeitos da expansão do comércio mundial para o Brasil & $+10 \%$ \\
\hline Desinformação sobre quem é responsável pela segurança alimentar no Brasil & $+9 \%$ \\
\hline Impacto dos EUA sobre o Brasil (média de 2 áreas) & $+7.5 \%$ \\
\hline
\end{tabular}

Média $=$ valor médio

Os achados para os itens selecionados mostram a falta de capacidade em formar opiniões que enfraquece os não-usuários, uma falta de capacidade igualmente forte para aspectos comerciais e sócio-políticos. Do lado dos usuários, encontra-se o grupo com maior probabilidade de identificar marcas e posicionar-se frente a aspectos básicos econômicos e políticos - pré-condições para escolher tanto produtos quanto idéias, serviços e programas de governo e, também, influenciar o resto da sociedade.

Tal especulação é reforçada pela extensão na qual membros dos dois grupos expõem níveis diferentes de conhecimento sobre questões contemporâneas. Quanto mais informado sobre questões, maior a probabilidade de que as opiniões expressas estejam embasadas em informação ou no uso de chaves de julgamento para tomar decisões. Como ensinam os psicólogos cognitivos e pensadores da 
escolha racional, sem algum grau de informação, dificilmente podem ser constituídas atitudes ou comportamentos.

Pode-se testar a diferença de conhecimento entre os dois grupos sobre questões específicas da agenda do país, observando a porcentagem de respostas que revelam ignorância ou perda de informação (ou seja, 'não ouvi nada sobre', 'não sei', 'não saberia o que dizer/ não pensei o suficiente sobre', 'não tenho informação suficiente').

Os dados reforçam a idéia de uma clivagem formada pelo uso da Internet, revelando quão ampla é a desinformação entre os não-usuários.

Hipótese 2: Contraste de hábitos e crenças individuais entre usuários e nãousuários

A experiência da Internet vai além do simples aspecto dos graus ou meios de informação e formação de opinião e reflete contrastes-chave de costumes e visões de mundo, uma vez que sua prática de acesso é internalizada. Essas disparidades podem ser reconhecidas através do exame de inclinações individuais no domínio privado.

Diferenças importantes entre usuários e não-usuários podem ser encontradas no domínio dos hábitos e crenças individuais, o que pode ser confirmado através do enfoque sobre um conjunto de reações e comportamentos habituais.

Tabela 5

Contrastes entre Hábitos e Crenças individuais entre usuários e não-usuários de Internet

(\% diferença para não-usuários)

\begin{tabular}{|c|c|}
\hline Tipo de Costume/Hábito & $\%$ Difer. \\
\hline Não gasta tempo com exercícios & $+33 \%$ \\
\hline Tempo médio gasto assistindo TV (horas por semana) & $+9.5^{*}$ \\
\hline Tempo médio lendo jornal(horas por semana) & $+0.9 *$ \\
\hline Tempo médio lendo revistas (horas por semana) & $.0 .5^{*}$ \\
\hline \multicolumn{2}{|l|}{ Crenças individuais } \\
\hline Acho que o modo antigo de viver e fazer as coisas é melhor & $+24 \%$ \\
\hline Antes de comprar algum produto novo tenho que ver alguém usando-o & $-17 \%$ \\
\hline Avanços tecnológicos tornam nossas vidas mais fáceis & $.8 \%$ \\
\hline $\begin{array}{r}\text { As pessoas deveriam gastar mais tempo vivendo o presente do que se } \\
\text { preocupando com o futuro. }\end{array}$ & $5 \%$ \\
\hline
\end{tabular}

* diferenças médias são estatisticamente significantes a $p<.10$ ou mais 
Diferenças entre os dados apontam que a vida dos usuários de Internet parece ser mais policromática do que a dos não-usuários: fazem mais exercícios e gastam menos tempo assistindo TV para fazer outras coisas (como por exemplo, o uso da Internet, mas não apenas isso). Além disso, os usuários de Internet destacam-se pelo seu pioneirismo, abertura a novos estímulos, e adoção precoce do ambiente digital e, de forma menos marcante, pelo entusiasmo pela tecnologia e pelo que pode ser chamado de "ethos do imediato". Por sua vez, os não-usuários são mais apegados aos "velhos costumes" e revelam um maior conservadorismo moral e de consumo, tanto no que se refere a tradições sociais como à sua relação com a tecnologia e produtos em geral.

As implicações desses achados são muito relevantes: os usuários da Internet são expostos a uma gama mais ampla de fontes de socialização. Essa pluralidade de estímulos de conhecimento provavelmente os torna menos convencionais em suas preferências. Por outro lado, não usuários são mais propensos a exibir visões estandardizadas comunicadas através da TV - algo que é especialmente verdade no Brasil, onde uma emissora, a Rede Globo, detém mais de $80 \%$ de audiência.

Hipótese 3: Contrastes de prioridades de temas e políticas e preferências por política

As diferenças entre níveis de informação e capacidades de formar opiniões, ao lado de distintos costumes e crenças, projetam-se sobre as escolhas que as pessoas podem fazer. Não é apenas um problema de recurso a diferentes mecanismos de aquisição de dados, mas que envolve diferentes agendas entre públicos. Nesse sentido, emergem prioridades e posicionamentos conflitantes sobre políticas entre usuários e não-usuários da Internet, resultantes de uma divisão nas oportunidades para acessar novos estímulos e do diferente perfil cultural desenvolvido a partir de tal divisão.

Examino essa proposição revisando concordâncias com afirmações distintas por parte de cada subgrupo para um conjunto específico de tópicos. 


\section{Tabela 6 \\ Contrastes de prioridades e preferências por políticas (\% diferenças para não-usuários)}

\begin{tabular}{|c|c|}
\hline Questões/ Aspectos sobre políticas & $\%$ Difer. \\
\hline \multicolumn{2}{|l|}{ Prioridades governamentais } \\
\hline Educação/escolas & $14 \%$ \\
\hline Economia (geral) & $.5 \%$ \\
\hline Crime / violência & $+8 \%$ \\
\hline Pobreza & $+6 \%$ \\
\hline Empregos/Desemprego & $+5 \%$ \\
\hline \multicolumn{2}{|l|}{ Governo deveria gastar mais em ... } \\
\hline Defesa & $+19 \%$ \\
\hline Benefícios aos pobres & $+8 \%$ \\
\hline Infra-estrutura pública & $.7 \%$ \\
\hline Arte \& cultura & $.13 \%$ \\
\hline \multicolumn{2}{|l|}{ Prioridades Nacionais para os próximos 5 anos } \\
\hline Manter a ordem pública & $.5 \%$ \\
\hline Proteger a liberdade de expressão & $+5 \%$ \\
\hline Lutar contra os preços & $+7 \%$ \\
\hline \multicolumn{2}{|l|}{ Objetivos dos governantes para os próximos 5 anos } \\
\hline $\begin{array}{r}\text { Reduzir a desigualdade social deixando o crescimento econômico em } 2^{\circ} \text { lugar } \\
\text { (em vez de favorecer o crescimento econômico e deixar a desigualdade em } 2^{\circ} \\
\text { lugar })\end{array}$ & $.7 \%$ \\
\hline \multicolumn{2}{|l|}{ Preocupado com o desemprego } \\
\hline \% "muito preocupado" & $+10 \%$ \\
\hline \multicolumn{2}{|l|}{ Preferências sobre impostos /gastos } \\
\hline $\begin{array}{r}\text { Governo deveria gastar menos em serviços sociais de forma a reduzir os } \\
\text { impostos (em vez de gastar mais e taxar mais) }\end{array}$ & $+18 \%$ \\
\hline \multicolumn{2}{|l|}{ Melhor forma de melhorar a situação da economia e do emprego no Brasil } \\
\hline $\begin{array}{r}\text { Retirar as restrições às importações para expandir o comércio com os outros } \\
\text { países (em vez de proteger indústrias locais e restringir importações) }\end{array}$ & $.11 \%$ \\
\hline
\end{tabular}


Usuários da Internet preocupam-se com questões de impacto a longo prazo, tais como a educação, e com expressões mais amplas da economia atual. Ao contrário, os não-usuários estão centrados nas conseqüências materiais e físicas de suas preocupações econômicas, como desemprego e taxas de criminalidade, além dos meios mais imediatos de reverter tais preocupações (ou seja, maior crescimento econômico, mais benefícios aos pobres, combate à alta de preços, menor pressão fiscal). São também mais propensos a apoiar gastos em defesa e mais sensíveis a argumentos protecionistas - preferências que acompanham o que tem sido denominado matriz estado-cêntrica de pensamento econômico, que prevaleceu no Brasil e em outros países da América Latina durante a segunda metade do século passado.

Comparativamente, os usuários parecem levemente mais inclinados a fazer uma escolha responsável por governos que gastam em serviços sociais (aceitando seus custos) e dão prioridade à questão da desigualdade social. Esta posição, entretanto, não significa apenas uma opção pela causa social mas, à luz de suas prioridades gerais, centradas na educação, infra-estrutura e aspectos econômicos globais, significa uma preocupação com as bases de longo prazo desses problemas.

Uma leitura conjunta dos achados revela um quadro sobre os usuários da Internet que mostra preferências liberais responsáveis em favor da liberdade de expressão na esfera individual (e, consistentemente com isso, apostando na educação, arte e cultura) e livre comércio sem restrições na esfera econômica, sem perder de vista as conseqüências que isso acarreta, a longo prazo, para o desenvolvimento econômico. Por outro lado, os não-usuários emergem como um grupo com valores materialistas tradicionais e na defensiva, centrado em resultados imediatos e caracterizado pelo conservadorismo.

\section{Hipótese 4: Contraste de atitudes com relação a atores e instituições}

Preferências contrárias também tendem a projetar orientações divergentes com relação a instituições existentes, com importantes conseqüências quanto à confiança e investimento psicológico. Há uma divisão que separa usuários e nãousuários quanto à credibilidade em instituições e atores globais. 
Tabela 7

Falta de Confiança em instituições entre usuários e não-usuários de Internet (\% diferença para não-usuários)

\begin{tabular}{|c|c|}
\hline Instituições & $\%$ Difer. \\
\hline \multicolumn{2}{|l|}{ Confiança em instituições internacionais } \\
\hline Efeitos do comércio mundial para o Brasil ('ajuda') & $.13 \%$ \\
\hline Nações Unidas & $\cdot 11 \%$ \\
\hline Empresas multinacionais & $\cdot 10 \%$ \\
\hline Organização Mundial do Comércio & $.9 \%$ \\
\hline Banco Mundial & $.9 \%$ \\
\hline \multicolumn{2}{|l|}{ Confiança nas realizações locais } \\
\hline Situação do meio ambiente (muito boa + boa ) & $+13 \%$ \\
\hline Trabalho do governo sobre meio ambiente(muito bom + bom) & $+9 \%$ \\
\hline \multicolumn{2}{|l|}{ Confiança em grupos (profissionais) no país } \\
\hline Autoridades religiosas & $+18 \%$ \\
\hline Jornalistas & $+15 \%$ \\
\hline advogados & $+11 \%$ \\
\hline Médicos & $+10 \%$ \\
\hline Policiais & $+9 \%$ \\
\hline Professores & $+6 \%$ \\
\hline Políticos & $+5 \%$ \\
\hline
\end{tabular}

Os usuários não são ingênuos nem tampouco cegamente negativos em relação a instituições e grupos, mas são distintos do cidadão médio. Em termos comparativos, sustentam um misto de crença internacionalista em atores globais com uma suspeição contra grupos institucionais brasileiros.

Ao nível doméstico, parecem estandartes de uma cultura adversária, não conformista, afetada por uma menor confiança em dois níveis, quais sejam, com relação às respostas governamentais a problemas coletivos específicos, como o meio ambiente, e com relação a grupos-chave que agem localmente. Portanto, na esfera local prevalece a não-conformidade; mas, ao nível global, exibem um importante grau de otimismo. Não se pode dizer, porém, se isso é uma manifestação de prévio reconhecimento de instituições globais visíveis emergentes ou apenas uma outra forma de convencionalismo. 


\section{Hipótese 5: Contraste entre níveis de engajamento coletivo}

Todas as diferenças previamente analisadas têm conseqüências na esfera da ação, para consumidores e para cidadãos. Cada grupo apresenta uma inclinação distinta para o engajamento coletivo e participação, e isso pode ser examinado observando como reagem a vários cenários.

\section{Tabela 8}

Diferenças em engajamento entre usuários e não-usuários de Internet (\% diferença para não-usuários)

\begin{tabular}{|r|c|}
\hline Tipo de Atividade & $\%$ Dif. \\
\hline Discutir sobre política com amigos/parentes (muito+quase sempre) & $\cdot 24 \%$ \\
\hline Engajado em boicote contra empresa de produtos específicos & $\cdot 13 \%$ \\
\hline Há formas em que pessoas como eu influenciam a política (concorda) & $\cdot 11 \%$ \\
\hline Auto-posicionamento ideológico (\% não sabe/não responde) & $+9 \%$ \\
\hline Nunca lê rótulos de produtos & $+8 \%$ \\
\hline Identificação partidária (\% nenhuma + não sabe/não responde) & $+6 \%$ \\
\hline
\end{tabular}

Os dados mostram que os usuários de Internet são mais envolvidos e sentem-se mais competentes do que os não-usuários para manifestar seus pontos de vista. São consumidores pró-ativos e poderiam ser cidadãos participativos, prontos para mobilização.

\section{Efeitos da Internet ou efeitos de classe?}

Essa rápida análise dos achados endossa as hipóteses das diferenças entre usuários e não-usuários da Internet no Brasil. Mas, à luz do quase monopólio do acesso pelas classes mais altas, poder-se-ia perguntar em que medida esses contrastes não refletiriam divergências de classe, ao invés de efeitos reais da Internet? Em outras palavras, como podemos saber que isso não é apenas um produto de associação espúria?

Argumento que esses efeitos são reais. Sua verificação pode ser feita checando se as diferenças mantêm-se quando itens são contrastados entre usuários e não-usuários dentre membros das classes $A$ e B: 


\section{Tabela 9}

Efeitos da Internet dentro dos segmentos $A$ e $B$ (\% diferença para não-usuários $A+B$ comparados a usuários $A+B$ )

\begin{tabular}{|c|c|}
\hline Questão de não-opinião & \% Dif. \\
\hline Não ouviu sobre a proposta de cancelamento da dívida do Terceiro Mundo & $+31 \%$ \\
\hline Não ouviu sobre alimento geneticamente modificado & $+28 \%$ \\
\hline $\begin{array}{r}\text { Desinformação sobre as principais marcas internacionais II (\%média de } 6 \\
\text { marcas) }\end{array}$ & $+21 \%$ \\
\hline Sem Opinião/Não Sabe sobre a OMC & $+20 \%$ \\
\hline Não ouviu /não sabe sobre o conflito no oriente médio & $+16 \%$ \\
\hline Nunca ouviu/ não sabe sobre o efeito Bug no Brasil & $+11 \%$ \\
\hline Desinformação sobre as principais marcas internacionais I (\% média de 5 marcas) & $+11 \%$ \\
\hline \multicolumn{2}{|l|}{ Hábitos e crenças individuais } \\
\hline Avanços tecnológicos tornam nossas vidas mais fáceis (concorda) & $\cdot 12 \%$ \\
\hline Não gasta tempo com exercícios & $+22 \%$ \\
\hline $\begin{array}{l}\text { Prioridades -Prioridades governamentais } \\
\text { Geral }\end{array}$ & $\cdot 10 \%$ \\
\hline Governo deveria gastar mais em. & $+12 \%$ \\
\hline $\begin{array}{l}\text { Meta nacional para os próximos } 5 \text { anos } \\
\text { expressão }\end{array}$ & $16 \%$ \\
\hline \multicolumn{2}{|l|}{ Posicionamentos sobre questões } \\
\hline Confiança na OMC & $+23 \%$ \\
\hline Situação do meio ambiente (muito boa+boa) & $+13 \%$ \\
\hline Engajado em boicote: contra empresas de produtos & $-12 \%$ \\
\hline
\end{tabular}

Uma comparação de diferenças de subgrupos igual ou maior que $10 \%$ entre itens selecionados mostra que a maioria dos efeitos da Internet mantém-se ${ }^{3}$, particularmente em relação à articulação de opinião e preferências por questões e políticas.

Isso significa que os usuários de Internet podem ser tratados como um grupo excepcional em si mesmo - a forma com que se comportam e percebem a realidade é singular e isso tem a ver com a maneira em que se dá sua interação com a Internet. Essa vanguarda digital pode vir a refletir as futuras modalidades de

\footnotetext{
${ }^{3}$ Uso uma diferença percentual mais exigente devido ao menor número de casos em cada célula, facilitando, assim, o uso do teste de significância estatística.
} 
consumo e comportamentos sócio-políticos. Mais ainda, isso ocorre em oposição às formas como as tradicionais elites de classe alta tem se comportado no Brasil.

\section{Dimensões da Cibercultura}

O mundo digital é caracterizado por uma cultura monolítica? Deveria ser tratado como um bloco homogêneo? É usual que as discussões feitas pela mídia considerem as pessoas que utilizam a Internet como um grupo só. Por outro lado, as poucas análises existentes, freqüentemente, têm utilizado alguns aspectos peculiares para classificar tipos específicos de usuários, isto é, admitindo divisões suficientemente fortes entre os internautas, de modo a encorajar a construção de tipologias.

Naturalmente, uma fonte multifacetada de socialização como a Internet tende a abrigar diferenças de objetivos e premissas entre o público que nela interage. De forma análoga, pode-se ter a expectativa de gerar padrões específicos de relacionamento e compreensão sobre o que a Internet representa e como se permite que molde as escolhas e pontos de vista. Isso significa que a atenção às diferenças internas pode ter conseqüências para compreender e abordar essa elite.

Nos últimos anos, emergiu o debate entre mídia e atores da indústria sobre esse tema, como tentativas de mapear e definir tanto o núcleo como os aspectos exclusivos dessa nova cultura, tendo por dilema tratar os usuários da Internet como um único grupo social ou admitir a existência de diferenças decisivas que justifiquem a segmentação dos sujeitos.

\section{A intensidade da dimensão de uso}

Ensaios clássicos sobre segmentação em marketing ensinam a pensar a intensidade de uso de um produto como a variável de corte. Isso ocorre com os usuários de Internet, tendo como divisor de águas os usuários considerados 'intensos' e os considerados 'leves', em função do número de dias/horas ou qualquer unidade de tempo de uso. Isso é clássico e familiar e assim tem sido usado e abusado.

Mas isso realmente ajuda? Dois problemas emergem, um relacionado à medida e outro ao conteúdo:

a) Sobre a medição: como decidimos sua medição, dado que não há um padrão único? Ou seja, qual número de horas? Número de dias? Número de acessos? Em uma semana? Em um mês? E quando estabelecemos a linha limítrofe? Mais de quantas horas distinguiriam um "usuário intenso" de um "usuário leve"? E o que seria pior, essas múltiplas medidas estariam apontando na mesma direção? Isso 
não parece ocorrer quando observamos o cruzamento de duas dessas medidas, como mostra a Tabela a seguir:

Tabela 10

Cruzamento de duas medidas diferentes de intensidade de uso (distribuição do total de casos)

\begin{tabular}{|c|c|c|c|}
\hline & \multirow{2}{*}{\multicolumn{2}{|c|}{ Freqüência de acesso por mês }} \\
\hline & & & \\
\hline & & Usuários intensos & Usuários leves \\
\hline \multirow{2}{*}{$\begin{array}{l}\text { Número de horas por } \\
\text { semana }\end{array}$} & Usuários intensos & $25 \%$ & $6 \%$ \\
\hline & Usuários leves & $11 \%$ & $57 \%$ \\
\hline
\end{tabular}

A Tabela 10 mostra que apenas um quarto dos usuários intensos classificados segundo um critério são classificados da mesma forma na outra categoria ${ }^{4}$. Dados não agrupados (ordinais $X$ intervalo) produzem uma correlação Pearson não-significativa de .015 .

b) Sobre conteúdo: A intensidade revela alguma coisa substantiva sobre a natureza da interação do usuário de Internet, ou seja, além dos graus contrastantes de estímulo pelo uso e disponibilidade de tempo? Em teoria, não. O que é decisivo para os dois protagonistas - usuários 'intensos' e leves'- é que estão do lado da equação em que está o usuário. Dentro desse grupo, os exame dos padrões de intensidade de uso, como uma forma de compreender as diferenças intragrupos, tende a produzir resultados mistos: alguns podem ser usuários intensos porque têm mais tempo disponível, enquanto para outros sua ocupação pode forçá-los a acessar a Internet mais freqüentemente do que a média. Em outras palavras, intensidade pode ser uma função de fatores exógenos para a interação do usuário e da Internet em si.

O contexto da dimensão de uso

Uma abordagem mais sociológica enfatiza que o ambiente no qual ocorre a interação entre usuário e Internet é o que mais importa: condições ambientais moldariam o uso. Elas moldam o alcance e os tipos de usos que podem ser desenvolvidos, de forma que terminam por moldar a agenda de interesses ligados à Internet, da mesma forma que as orientações básicas com relação a ela.

\footnotetext{
4 Apesar do fato de ambas renderem proporções aproximadas de usuários 'intensos' e 'leves': $36,5 \%$ de 'intensos' quando se usa o indicador de "freqüência de acesso por mês" e 31\% quando se usa "número de horas por semana”. O restante, nos dois casos, eram usuários 'leves'.
} 
Mesmo que não esteja explicitamente colocado, parece plausível o argumento por trás da intenção de distinguir entre "usuários domésticos" e "nãodomésticos", estes últimos tendencialmente denominados "usuários ocupacionais", dado que seu acesso ocorre predominantemente em seus trabalhos ou escolas/faculdades. Em alguma medida, este é o ponto de vista apresentado pelo jornal Folha de São Paulo e seu servidor UOL, ambos tendo usado e retratado o mundo da Internet a partir desta perspectiva (Folha de S. Paulo, 1999). É certo que a diferença entre usuário 'doméstico' e “não-doméstico" é relevante e pode-se facilmente concordar com o raciocínio proposto. Então, como se adequa o processo de escolha do indivíduo por trás de qualquer ação, quando utilizando a Internet pelos usuários? Todas essas trocas são meros resultados de causas exógenas - as limitações /oportunidades definidas pelo ambiente de acesso? Pode-se, de forma válida e realista, reduzir todas as relações com a Internet a um único determinante, o contexto? Infelizmente, essas questões permanecem não elaboradas. Dessa forma, essa abordagem tornou-se útil para ilustrar as imperceptíveis ligações presentes na cultura da Internet, mas incapaz de propiciar uma resposta substantiva para o tema das dimensões influentes envolvidas.

\section{A dimensão da conectividade}

Há pouco tempo jornalistas especializados e observadores da indústria, sobretudo dos Estados Unidos, preferiram enfatizar o grau de conectividade como uma variável decisiva para mapear as diferenças internas entre usuários da Internet.

Essa medida foi construída sobre um índice somatório de equipamentos tecnológicos usados ou possuídos por usuários, criando uma polaridade entre os hiper-conectados (aqueles que usam/possuem todos os equipamentos) e os moderadamente conectados (os que usam/possuem ao menos um deles). Deixamos de lado os "não-conectados", que coincidem com o conjunto de "não-usuários". Uma série de fóruns de discussão financiada pela Wired a partir de 1997 conduziu o caminho desse enfoque.

O problema deste enfoque é que o grau de conectividade parece mais uma medida de riqueza e curiosidade tecnológica do que uma pista que ajude a pensar as diferentes atitudes e comportamentos. Como resultado, proporciona uma contribuição não clara à questão de como a interação dos usuários com a Internet promove diferenças e como explicar tais diferenças.

Em conclusão, essas tentativas em revelar diferenças dentro da cibercultura emergente propiciaram taxonomias interessantes, mas avaliações não-práticas ou não-válidas das dimensões internas da cultura de uso da Internet.

Tais estratégias sofrem de problemas distintos. 0 mais importante e básico deles é que são levadas a descrever as condições previamente necessárias ao 
desenvolvimento de uma prática de Internet. São todas relacionadas ao que faz um indivíduo tornar-se um usuário: disponibilidade de tempo, motivação para 'ligar-se', disponibilidade de ambiente ou infra-estrutura, disponibilidade de recursos para adquirir bens instrumentais para conectar-se. Mas são medidas pobres de cibercultura, ou seja, de como este usuário de Internet de fato se relaciona e interage com o meio, e que impacto a Internet tem sobre ele/ela nas suas esferas básicas de vida: como consumidores e como cidadãos.

Medidas regularmente usadas conduzem, portanto, a dois erros básicos:

a) "colocam o carro na frente dos bois", interpretando como efeito o que de fato vem primeiramente como causa ou pré-condição para tais práticas e usos. De fato, os padrões de interação entre usuário e Internet são possíveis uma vez que a infra-estrutura, acesso e tempo estão disponíveis, e não de outro modo;

b) elas reificam o que é comumente entendido como cultura, ligando-a à quantidade de práticas e usos ou à base física/material que torna possível tais práticas e usos, ao invés de revelar significados peculiares e correlatos atitudinais dessas práticas e usos. Mas o conteúdo da interação usuário-Internet dificilmente pode ser resumido pela quantia de tempo gasto ou de bens tecnológicos possuídos ou utilizados.

\section{A dimensão funcional: intelectual e recreativa}

Minha sugestão é que padrões de uso, ou seja, os motivos e a freqüência com que os usuários acessam a Internet, é uma forma muito melhor de abordar essas diferenças e de construir uma segmentação válida tanto para as pesquisas político-sociais como para as iniciativas de marketing. O foco vai para a funcionalidade dada pelos usuários à Internet, que emerge como um problema de dimensões de engajamento entre ela e os usuários.

A premissa é que as pessoas abordam e usam a Internet por razões distintas, sem levar em conta suas oportunidades de tempo, materiais e contextuais. Não se trata daquilo que faz com que usem a Internet, mas de como terminam relacionadas a ela. E a proposição aqui é que duas dimensões básicas estão presentes em cada usuário com maior ou menor intensidade:

1) a primeira, que pode ser denominada "intelectual" e envolve atividades mais instrumentais, extrativas, orientadas por objetivos, como "baixar" arquivos e programas, buscar informações, coletar e ler notícias e as rotinas de correio eletrônico;

2) a segunda, que pode ser denominada "recreativa" e envolve atividades de comunicação auto-contidas, orientadas para o lazer, como assistir vídeos e filmes, ou escutar música, conversar e usar o ICQ. 
Para medir esse construto, a seguinte questão foi aplicada em surveys com a população geral em duas ocasiões recentes:

"Em um mês típico, com que freqüência você diria que realizou as seguintes atividades na Internet?" sempre/quase sempre; algumas vezes; raramente/quase nunca; nunca?

enviar/receber mensagens

ouvir música

discussão

'baixar' arquivos

fazer pesquisa (para trabalho ou escola)

utilizar o ICQ

ver vídeos e filmes

A vantagem desta questão em relação às medidas anteriores é que ela contém tanto a avaliação qualitativa quanto a quantitativa. Minha hipótese é que tal variável de interação usuário-Internet tem o potencial de revelar as duas dimensões funcionais decisivas do uso da Internet, cada uma delas definindo um foco específico de prática e projetando-se com diferenças importantes sobre disposições políticas e comerciais. Esses não são conjuntos ou segmentos distintos de usuários, mas representam dimensões distintas de uso ou tendências sub. culturais.

\section{Verificando a validade da abordagem dimensional}

Para obter a validade empírica desse construto, realizei uma análise de componentes principais, utilizando a mais simples opção de rotação (Varimax com normalização Kaiser), e retirando da análise os 'scores' menores que .40, com objetivo de ganho em destaque em cada fator. Esse procedimento foi realizado com duas diferentes amostras para checar a validade. Os dois surveys foram realizados nos cinco maiores centros urbanos brasileiros, com uma amostra representativa da população adulta, sendo o primeiro em Julho de 2000 e o segundo em Novembro/Dezembro de 2000.

A análise de componentes principais foi aplicada apenas na sub-amostra dos chamados usuários de Internet, e nas duas situações foram encontrados dois fatores com as seguintes características: 
Tabela 11

Análise de Componentes Principais das funções do uso da Internet

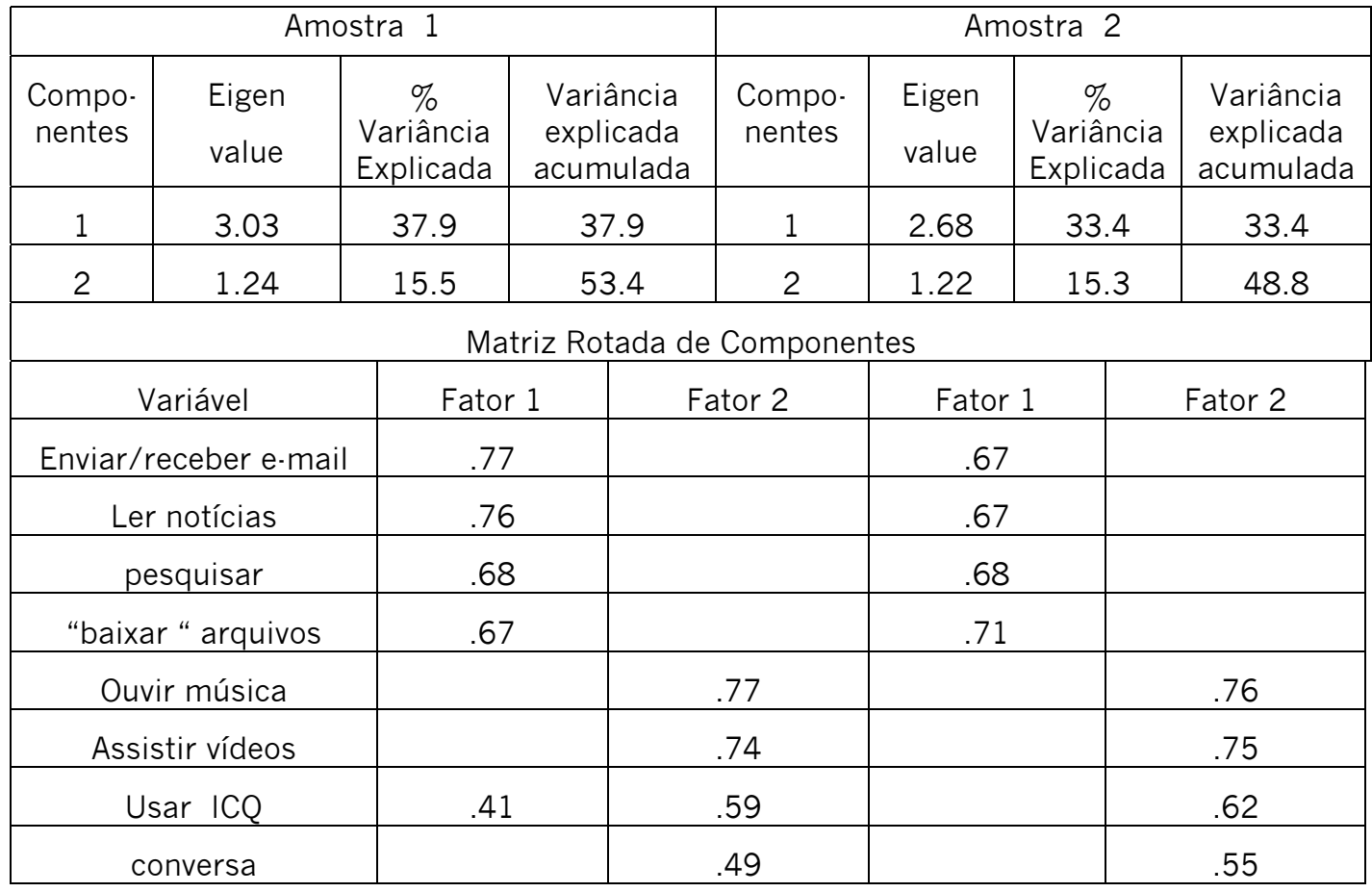

Os resultados para as duas amostras produziram achados razoavelmente similares. Em primeiro lugar, há dois grupos distintos atrás da diversidade de ações funcionais assumidas pelos usuários, e essas duas dimensões correspondem aos modos de uso em hipótese. Em segundo lugar, esses grupos são razoavelmente consistentes entre as diferentes amostras e períodos, revelando um grau de confiabilidade - se é verdade que a ordem das variáveis rodadas varia entre as amostras para o primeiro componente, o grau de desvio é mínimo e não define uma contradição à proposição básica. Finalmente, os 'scores' são muito estáveis no tempo e entre amostras.

Isso revela que uma abordagem bi-dimensional centrada nas relações funcionais com os usuários da Internet é válida. O que ainda se deve provar é que isso também é substantivo do ponto de vista de sua contribuição para nossa compreensão sobre a mente dos usuários e os efeitos da Internet. 


\section{Avaliando o efeito relativo da abordagem funcional}

Para medir o peso relativo dessa abordagem dimensional enfocada nos modos de uso frente às abordagens tradicionais, realizei uma análise multivariada de seus efeitos sobre uma série de variáveis com relevantes implicações sóciopolíticas e comerciais.

Essas ferramentas analíticas multivariadas (regressão múltipla e regressão logística simples) buscam examinar a significância estatística dos efeitos dos diferentes modos de interação entre usuário e Internet em termos de sua relativa força de co-variação com medidas-chave comportamentais e atitudinais.

Efeitos não-significativos para uma abordagem específica denotariam quão marginalmente ela influencia os usuários de Internet nas suas escolhas comerciais e sócio-políticas. De outro lado, quanto mais alta a variação significativa de alguma dessas abordagens com tais manifestações da vida cotidiana, mais isso revelará quão central é tal abordagem para a compreensão das ações e opiniões dos usuários.

A hipótese aqui é que há implicações sócio-políticas e comerciais decisivas geradas pelos efeitos da perspectiva funcional nas questões do dia-a-dia. Além disso, as perspectivas alternativas (ou seja, intensidade, contexto e conectividade) são incapazes de explicar a dinâmica de uso da Internet ${ }^{5}$.

Uma vez que a dimensionalidade intelectual-recreativa define efeitos diferentes para cada função particular, optei por apresentar os resultados por componente de forma individual. Meu entendimento é que isso permitiria tanto avaliar o efeito relativo da abordagem funcional quanto ilustrar as variações internas.

\footnotetext{
${ }^{5}$ A dimensão da intensidade foi medida usando as seguintes questões: "Em um mês regular, com que freqüência você diria que acessa a Internet". As opções de resposta eram: "menos que uma vez por mês, uma vez por mês, 2 a 3 vezes por mês, uma vez por semana, 2 a 3 vezes por semana, 4 a 6 vezes por semana, uma vez por dia, mais que uma vez por dia". Todas as primeiras 5 alternativas, mais a resposta 'não sei' foram agrupadas em uma única categoria denominada 'usuários leves', enquanto as 3 últimas alternativas, por sua vez, foram agrupadas como 'usuários intensos'.

A dimensão contextual foi medida pela questão: "Algumas pessoas acessam a Internet de casa, outros acessam do trabalho ou escola, enquanto outros acessam de outros locais, tais como a casa de alguém, a biblioteca pública, centro comunitário, órgão do governo, bar/café etc. De qual local, principalmente, você acessa a Internet?". As alternativas de resposta: de casa, do trabalho, da escola, casa de outras pessoa, biblioteca pública, centro comunitário, órgão do governo, bar/café, loja de computador, outro lugar". As respostas foram agrupadas em duas categorias principais: 'de casa' e ' do trabalho/escola/outros'. Cabe dizer que todas as alternativas exceto 'de casa' somaram menos que $5 \%$ das respostas.

A dimensão da conectividade foi medida como um índice somatório que incluía envio e recepção de e-mail "sempre/quase sempre"; posse de telefone celular e linha telefônica fixa, e posse/uso de computador. Cada variável adicionava um ponto ao índice, e este foi definido como uma escala ordinal com o máximo de 5 pontos (de 0 a 4 ).
} 
Tabela 12

Efeitos dos enfoques sobre hábitos e atitudes comerciais

\begin{tabular}{|c|c|c|c|c|c|}
\hline Variável chave & & & Enfoque & & \\
\hline Comprou on-line & Conectividade & Intensidade & Contexto & Intelectual & Recreativa \\
\hline Fora da temporada & .18 & & & & -.14 \\
\hline Alta temporada & & -.17 & & .10 & \\
\hline $\begin{array}{l}\text { Visitou páginas } \\
\text { comerciais }\end{array}$ & & & & -.15 & \\
\hline $\begin{array}{l}\text { Interesse em comprar } \\
\text { on-line (índice de } 11 \\
\text { itens) }\end{array}$ & $\cdot .20$ & & & $\cdot .24$ & .19 \\
\hline $\begin{array}{l}\text { Desinformação sobre } \\
\text { marcas }\end{array}$ & $\cdot .24$ & & & & \\
\hline
\end{tabular}

Dados são pesos beta ou correlações parciais estatisticamente significantes ( $p<.05$ ou melhor)

Células vazias significam efeitos não-significativos para aquele enfoque sobre aquela variável

Como mostra a Tabela 12, o peso relativo das distintas abordagens sobre hábitos específicos do consumidor está condicionado pela sazonalidade. Fora da estação, o grau de conectividade e das orientações recreativas molda significativamente a experiência de compra on-line - quanto mais conectado e mais orientado pela dimensão recreativa, maior é a incidência de compradores eletrônicos.

Mas as coisas mudam no ponto alto da estação: qualquer que seja o grau de conectividade, os usuários demonstram que não ajudarão a predizer seus dados de compra on-line. Tampouco fariam isso de forma a deixar conhecer seu contexto de interação com a Internet (o mesmo resultado que durante períodos fora da estação).

Ao contrário, a intensidade de uso ajudaria a fazer isso, com uma relação negativa peculiar, o que significa que, nesse período do ano, usuários 'leves' são proporcionalmente mais influentes comprando bens através da Internet.

Outro efeito relevante é apresentado pela dimensão intelectual: quanto menos o usuário é orientado intelectualmente, maior é a incidência de compra online. Uma conclusão preliminar é que a abordagem funcional está presente de uma forma que é estatisticamente significante, independente da estação. Isso não pode ser dito das demais abordagens. 
Outras questões importantes para análise do consumidor são os hábitos de visita a páginas de comércio, o nível de informação sobre marcas (nesse caso, eu meço o oposto: o grau de ignorância sobre as principais marcas) e o interesse em realizar compras on-line.

O que os dados revelam é que tanto a dimensão intelectual quanto recreativa delineiam de forma significativa intenções e curiosidades on-line, e que apenas o grau de conectividade aproxima-se em uma situação com resultados não significativos para os demais. Por outro lado, conectividade é a única variável que ajuda a compreender o que delineia o déficit de lembrança de marcas.

Diferenças também ocorrem no âmbito da vida social e política. Entre vários itens e índices testados que produzem coeficientes estatisticamente significantes, o cenário confirma a centralidade de dimensões funcionais caracterizando orientações de usuários.

Tabela 13

Efeitos de enfoques sobre atitudes sociais e políticas

\begin{tabular}{|l|c|c|c|c|c|}
\hline Variável chave & \multicolumn{5}{|c|}{ Enfoque } \\
\hline & conectividade & Intensidade & Contexto & Intelectual & Recreativa \\
\hline $\begin{array}{l}\text { Satisfação com trabalho } \\
\text { (índice de 6 itens) }\end{array}$ & & & -.22 & -.21 & \\
\hline $\begin{array}{l}\text { Crime como principal } \\
\text { prioridade }\end{array}$ & .20 & .20 & & & \\
\hline $\begin{array}{l}\text { Auto-suficiência } \\
\text { tecnológica }\end{array}$ &. .12 & & .18 & &. .15 \\
\hline $\begin{array}{l}\text { Democracia sem } \\
\text { partidos políticos }\end{array}$ & & -.23 &. .31 & .29 & .14 \\
\hline $\begin{array}{l}\text { Confiança em partidos } \\
\text { políticos }\end{array}$ & & & & .22 & \\
\hline Envolvimento político & & & & & \\
\hline
\end{tabular}

Dados são pesos beta ou correlações parciais estatisticamente significantes $(p<.05$ ou melhor)

Células vazias significam efeitos não-significativos para aquele enfoque sobre aquela variável 
Os achados mostram que vinculações "intelectuais" são extremamente importantes para delinear níveis de satisfação com o trabalho, envolvimento político e confiança nas instituições políticas, enquanto ligações "recreativas" são decisivas para entender a relação dos usuários de Internet com a tecnologia, e seu modelo de democracia. Como mostram os dados, essas dimensões podem não definir o mais alto 'score' na sua variação com cada item mas são claramente as que têm incidência mais freqüente.

As dimensões funcionais são melhor avaliadas do que as abordagens alternativas na definição de orientações e decisões comerciais e não comerciais, pois incorporam contornos substantivos de seu aspecto relacional com a Internet, em adição à inclusão de um sentido de intensidade. Essa perspectiva desenha de forma mais completa os esquemas de como usuários organizam seus pontos de vista e escolhas. Sendo assim, é mais provável prometer melhores resultados no momento da pesquisa sobre a forma em que os usuários reagirão às proposições comerciais e não-comerciais.

As implicações práticas de confirmar que os usuários ativos cultivam uma relação mais intelectual ou mais recreativa com a Internet, ao invés de enfocar o valor agregado da freqüência, contexto ou conectividade, parecem claras e importantes.

\section{Conclusões}

Falar sobre qualquer aspecto do mundo da Internet no Brasil representa um desafio e um risco, à luz do que sabemos sobre a sua velocidade de crescimento e sobre os ciclos de vida. Nos vinte minutos de leitura que levou este artigo, por exemplo, trinta e cinco novos brasileiros aderiram às fileiras dos usuários ativos de Internet. Entraram com seus próprios hábitos, conhecimento, prioridades e preferências mas, assim que o fizeram, começaram a combiná-los com os estímulos e a dinâmica de comunicação e pensamento propostos pelo mundo da Internet. Com o tempo, isso vai colocá-los à parte do fluxo dominante dos nãousuários, embora não vá escamotear certas diferenças específicas entre eles, relacionadas principalmente a como e por quais razões vieram a utilizar ativamente a internet. 
Essa breve ilustração de aspectos dos novatos condensa os três principais resultados da discussão desenvolvida nesse artigo:

1. Existe uma profunda diferença quanto aos hábitos, disposições políticoeconômicas e orientações de consumo entre usuários e não-usuários de Internet. Hoje, essa é a maior clivagem na sociedade brasileira, capaz de transformar-se, provavelmente, em tão importante quanto as clivagens regionais e de classe eram no passado recente. Usuários compram de forma distinta, têm diferentes relações com as marcas, mostram pontos de vista mais articulados e persuasivos, engajam-se mais profundamente na política e são menos convencionais em suas posturas sócio-políticas. As conseqüências de dar atenção a essa divisão deveriam ser claras para os atores de mercados políticos e de serviços e produtos.

2. Além disso, os usuários de Internet não conformam um grupo homogêneo e monolítico. Pode-se certamente encontrar sustentação empírica para as segmentações intra-grupos de todos os tipos: a intensidade de uso, os limites contextuais, ou os dados de sofisticação conectiva têm sido até agora as variáveis de corte populares encontradas pela indústria da Internet e de pesquisa de mercado. Entretanto, a contribuição dessas abordagens para compreender as subculturas divergentes abrigadas no uso da Internet e suas implicações para os investimentos comerciais e as iniciativas sócio-políticas são, em sua maior parte, pouco substantivas, se não enganosas.

3. O que importa é em que meios e por quais razões usuários de Internet tornam-se ativos e permanecem como tais. A ênfase poderia ser funcional, as dimensões poderiam estar relacionadas a seus padrões de interação com a Internet. Tal abordagem produz duas principais proposições contendo uma classificação mais substantiva e de maior significação dos usuários: uma premissa "intelectual" e uma premissa "recreativa". Cada uma representa um enfoque peculiar sobre como viver e cultivar a Internet, e essa classificação tem claras vantagens quando comparada com os efeitos dos modelos alternativos de perfilar usuários em aspectos-chave comerciais e políticos da vida. 


\section{Bibliografia}

Perfil do internauta Brasileiro, 1998-2000. Cadê/Ibope, Relatório Especial. Disponível em $<w w w$.ibope.com.br>.

Metade dos internautas brasileiros é carona. Folha de S.Paulo, Relatório Especial, 22 dez.1998.

GONÇALO JÚNIOR. E o cidadão digital brasileiro? Gazeta Mercantil, 4 abr. 1998.

KATZ, Jon. The birth of the digital nation, Wired, 5 abr. 1997.

. The digital citizen. Wired. The Resource Center for Cyberculture Studies, 1997.

LUNTZ, Frank. The WIRED/Merrill Lynch Forum Digital Citizen Survey. Merrill Lynch\&Co., Inc. 1997. Disponível em: <http://www.ml.com/woml/forum/results.htm>.

NICOLACI DA COSTA, Ana Maria. Na malha da rede. Rio de Janeiro: Ed.Campus, 1998. 